\title{
Conventional and Electromagnetic-induction Sintering of High Entropy Alloys for Low-temperature Applications
}

Luis Laguna Zubia ${ }^{1}$, C.G. Garay-Reyes ${ }^{2}$, M.A. Ruiz-Esparza-Rodriguez ${ }^{2}$, J.M. Mendoza-Duarte ${ }^{2}$, Ivanovich Estrada ${ }^{3}$, P.A. Guerrero-Seáñez ${ }^{4}$ M.A. Rascón-Sánchez ${ }^{5}$, J.P. Flores-De-los-Ríos ${ }^{5}$, R. Martínez-Sánchez ${ }^{2}$ and M.A. Castro-Reyes ${ }^{5}$

${ }^{1}$ Universidad Autónoma de Chihuahua, Facultad de Ingeniería., Meoqui, Chihuahua, Mexico, ${ }^{2}$ Centro de Investigación en Materiales Avanzados (CIMAV), Laboratorio Nacional de Nanotecnología, Chihuahua, Chihuahua, México, ${ }^{3}$ Centro de Investigacion en Materiales Avanzados SC, Chihuahua, Chihuahua, Mexico, ${ }^{4}$ Universidad Autónoma de Chihuahua, Chihuahua, Chihuahua, Mexico, ${ }^{5}$ Universidad Autónoma de Chihuahua, Facultad de Ingeniería, Chihuahua, Chihuahua, México

The sintering process compresses or densifies the powder particles to obtain solid samples from powders [1]. In this sense, two sintering routs were carried out this study, conventional and electromagneticinduction sintering. The conventional sintering consists of compacting in the powders by uniaxial pressure, and later, heats the samples in a furnace for long periods. The electromagnetic-induction sintering consists of heating and applying uniaxial pressure at the same time in the powders during short periods. Both routes present different effects in the systems presented in this work due principally to the high-entropy alloys consist of at least five elements, [2] and the difference between the melting point of each element that forms the alloy is very different.

The (AlCuNi) ${ }_{80} \mathrm{Sn}_{10} \mathrm{Zn}_{10}$ and $(\mathrm{AlCuNi})_{70} \mathrm{Sn}_{15} \mathrm{Zn}_{15}$ systems were studied. For conventional sintering, the powders were compacted with a uniaxial pressure of $1.5 \mathrm{Gpa}$ for $5 \mathrm{~min}$ using a die with a diameter of 6.4 $\mathrm{mm}$. Posteriorly, the samples were heated at $550{ }^{\circ} \mathrm{C}$ and $500^{\circ} \mathrm{C}$ for $(\mathrm{AlCuNi}) 80 \mathrm{Sn} 10 \mathrm{Zn} 10$ and (AlCuNi)70Sn15Zn15 systems, respectively, both for $10 \mathrm{~h}$ under argon atmosphere. For electromagneticinduction sintering, heating of samples for 10 and $5 \mathrm{~min}$ were evaluated in temperatures and pressure similar to mentioned for conventional sintering. X-Rays Diffraction (XRD), Scanning electron microscopy (SEM) and Transmission electron microscopy (TEM) were carried out the characterization of structure and microstructure. Vickers micro-hardness test was used to evaluate the mechanical properties. All samples were prepared using conventional micrographic technics.

The samples were sintering effectively by both routes. However, they present differences in their hardness according to the sintering route. It is shown in Figure 1 that both systems are a multiphasic FCC and BCC structure. Also, At long periods of heating, the hardness decreases as is shown in Figure 2, owing to the increase in particle size, which increases with temperature. 

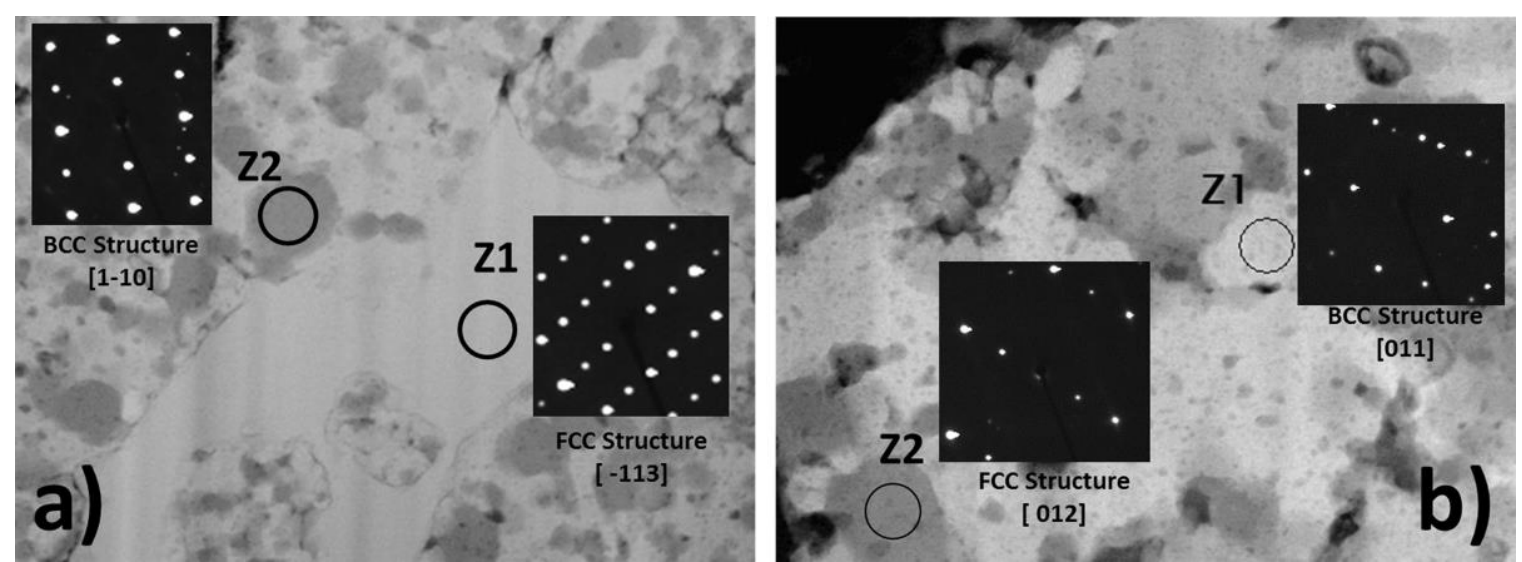

Figure 1. TEM Micrographs and corresponding SAED of (AlCuNi)80Sn10Zn10, a) Conventional sintering by 10 hours and b) electromagnetic-induction sintering by $10 \mathrm{~min}$

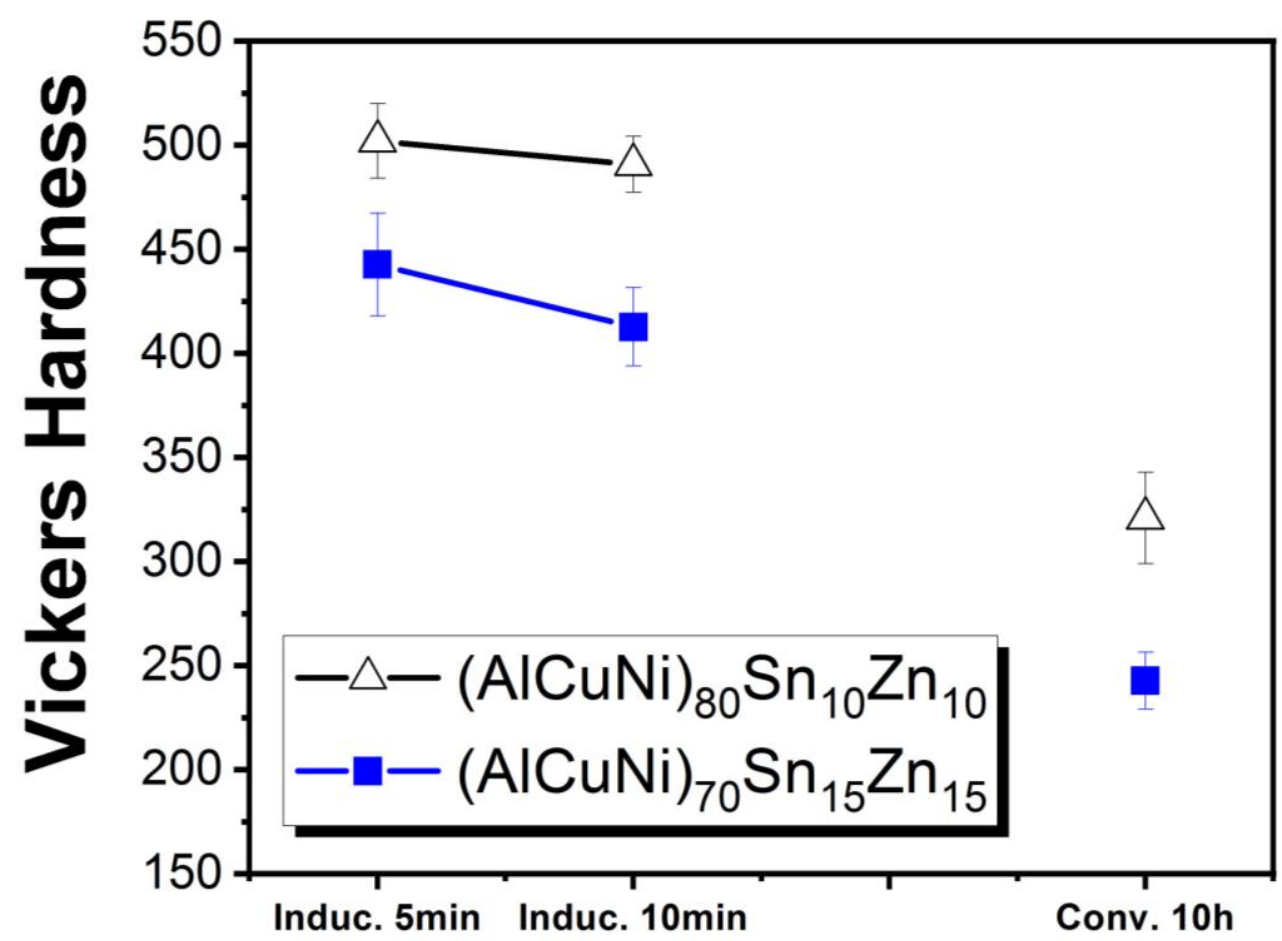

Figure 2. Comparison of microhardness values obtained in the samples trough conventional sintering and electromagnetic-induction sintering

References

[1] Schaffer J.P., Saxena A., Antolovich S. D., Sanders T.H. \& Warner S.B.. (2000). The science and design of engineering materials. Mexico: CECSA.

[2] Miracle D.B. , Miller J.D., Senkov O.N., Woodward C.,Uchic M.D. \& Tiley J.. (2014). Exploration and Development of High Entropy Alloys for Structural Applications. Entropy, 16, 494-525. doi:10.3390/e16010494 